\title{
Gasping on Oxygen: A Case Report on Toxic Methemoglobinemia
}

\author{
Mahavishnu Sahadevan, Menaka Mahendran², Subasini Govindan³, Thilagavathi Thanusia \\ Viswanathan 4
}

1 Department of Neurology, General Hospital, Kuala Lumpur, Malaysia

2 Department of Cardiology, Queen Elizabeth Hospital, Sabah, Malaysia

3 Department of Nephrology, Tuanku Ja'afar Hospital, Seremban, Malaysia

${ }^{4}$ Department of Internal Medicine, General Hospital, Ipoh, Malaysia

\section{CORRESPONDENCE}

Mahavishnu Sahadevan

Department of Neurology

Kuala Lumpur General Hospital

NO 23 Jalan Pahang

50586 Kuala Lumpur, WP, Malaysia

Tel: +60 166307740

E-mail: drmahavishnu@gmail.com

\section{ARTICLE HISTORY}

Received: November 27, 2020

Accepted: December 15, 2020
Menaka Mahendran - Department of Cardiology, Queen Elizabeth Hospital, 88200 Kota Kinabalu, Sabah, Malaysia. Tel: +60 123464 730, E-mail: drmenaka85@gmail.com

Subasini Govindan - Department of Nephrology, Hospital Tuanku jaafar, Jalan rasah, 70300 Seremban Malaysia. Tel: +60 190617 52, E-mail: subagovindan@ hotmail.com

Thilagavathi Thanusia Viswanathan • Department of Internal Medicine, Ipoh General Hospital, 30450 Ipoh Perak, Malaysia. Tel: +60 112424 0307, E-mail: thanusia82@yahoo.com

\begin{abstract}
We report the case of a 27-year-old male patient who presented with refractory hypoxemia following the alleged inhalation of an unknown substance. The patient appeared to show worsening cyanosis despite increment of supplemental oxygenation. A drawn sample of the patient's blood appeared chocolate brown in color, and disparity was noted between the patient's oxygen saturation $\left(\mathrm{SaO}_{2}\right)$ in his blood against the pulse oximetry $\left(\mathrm{SpO}_{2}\right)$ reading. A diagnosis of toxic methemoglobinemia was established following elevated levels of methemoglobin discovered in his blood. The patient was started on methylene blue and instantaneously recovered without any complications. Methemoglobinemia should be suspected in any patient with refractory cyanosis, and early recognition of this condition could be potentially lifesaving.
\end{abstract}

Keywords: cyanosis, methemoglobinemia, methylene blue

\section{INTRODUCTION}

Methemoglobin is an oxidized form of hemoglobin $(\mathrm{Hb})$, in which its hem iron configuration has been altered from its original ferrous $\left(\mathrm{Fe}^{2+}\right)$ state to an oxidized ferric $\left(\mathrm{Fe}^{3+}\right)$ state. In this oxidized state, the iron molecules are unable to bind and transport oxygen and carbon dioxide, which can lead to a myriad of health complications. Methemoglobinemia can be either congenital or acquired. The majority of people with the congenital form tend to be asymptomatic; however, acquired methemoglobinemia can be severe or even fatal.

\section{CASE REPORT}

A 27-year-old male patient, who worked in a plant fertilizer factory, presented to the emergency department in a reduced state of consciousness after the accidental inhalation of an unknown substance at his work place. 

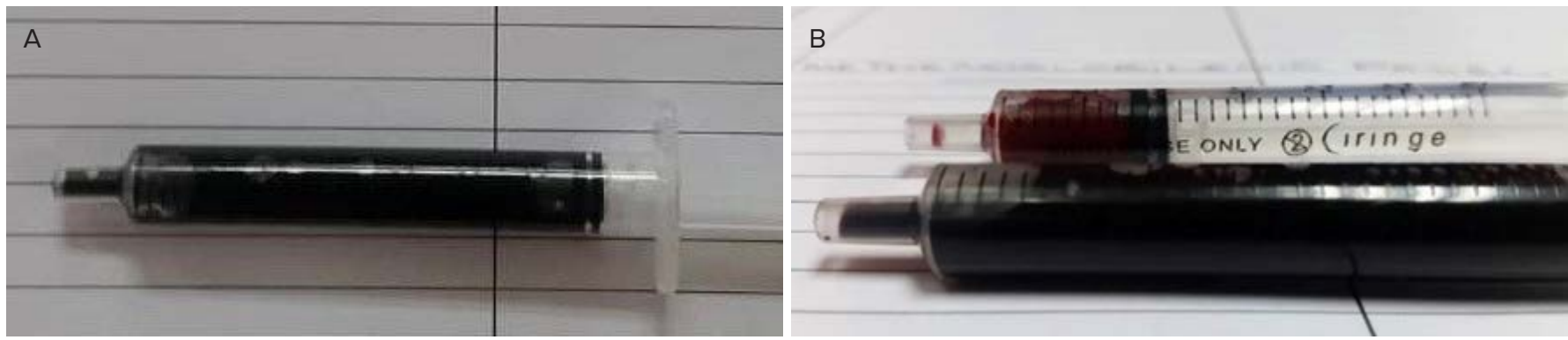

FIGURE 1. A - The patient's blood sample, which appeared dark brown; B - Comparison made with a normal blood sample
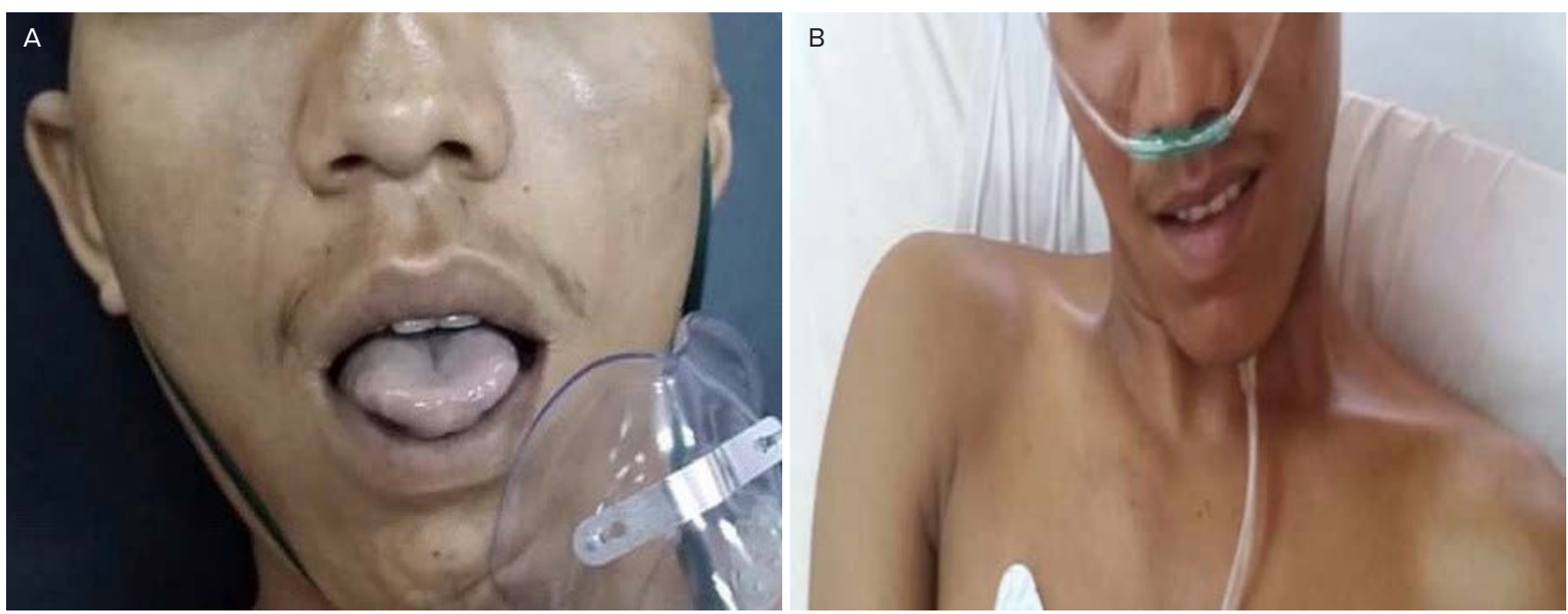

FIGURE 2. A - Before treatment; B - After treatment

He arrived cyanosed and out of breath, with a blood pressure of 100/60 $\mathrm{mmHg}$, a heart rate of $120 \mathrm{bpm}$, and a respiratory rate of 16 breaths/minute. The initial Glasgow

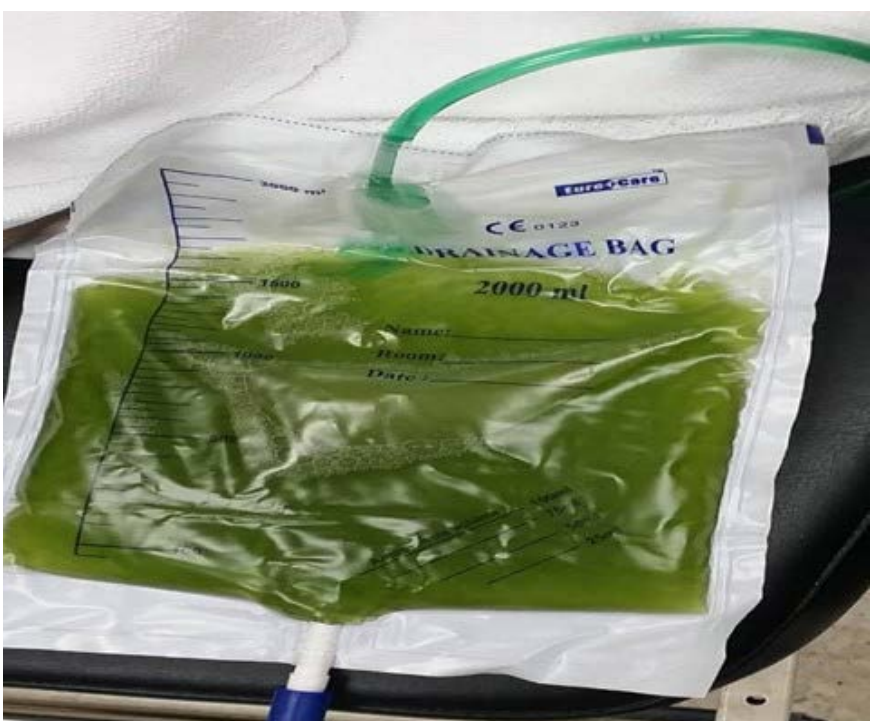

FIGURE 3. Greenish urine observed following the administration of methylene blue
Coma Scale (GCS) demonstrated an eye opening response to verbal stimuli, commands, and speech (E3), a motor response of withdrawal to pain (M4), and a verbal response of being confused but able to answer questions (V4).

Respiratory examination was unremarkable. However, the patient's pulse oximetry read $80 \%$ while on $100 \%$ supplemental oxygen via a rebreather mask. In the blood samples drawn the patient's blood appeared chocolate brown in color (Figure 1). The chest X-ray showed clear lungs.

Initial arterial blood gas showed a partial pressure of oxygen of $275 \mathrm{mmHg}$ with an oxygen saturation of $99.6 \%$. This disparity prompted us to consider that the pulse oximetry and arterial blood gas results might appear misleading, especially when two or more types of hemoglobin are present in a particular sample of blood. The peculiar color of the patient's blood added to the suspicion and prompted a direct measurement of oxyhemoglobin levels using a carbon monoxide ( $\mathrm{CO})$-oximeter, showing that the patient had indeed a methemoglobin (MetHb) level of $69.8 \%$ (normal value $1-2 \%$ ) in his blood.

A diagnosis of toxic methemoglobinemia was established, and the patient was started on intravenous methy- 


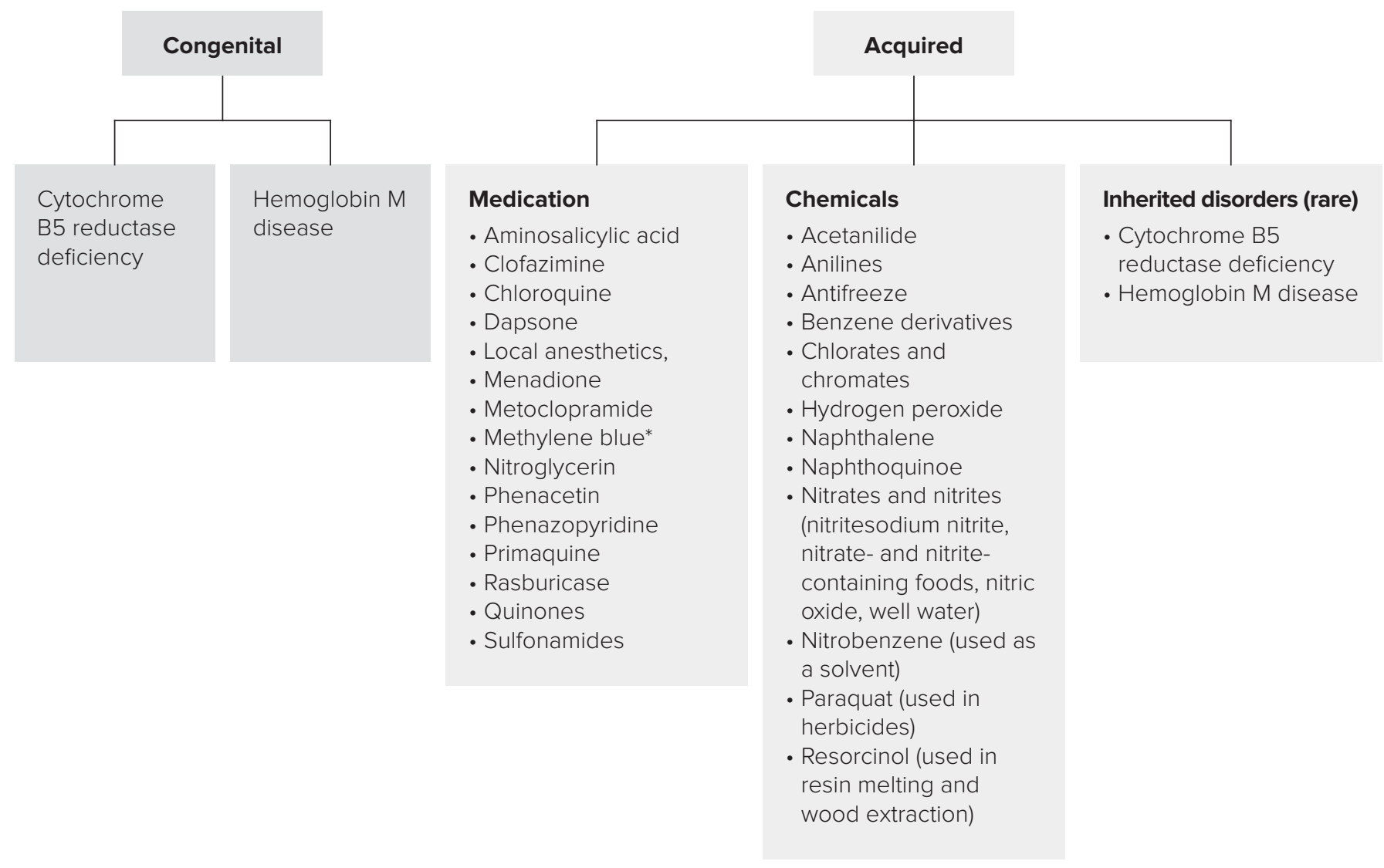

FIGURE 4. The most frequent causes of methemoglobinemia

lene blue (MB) at a dose of $1 \mathrm{mg} / \mathrm{kg}$ over 5 minutes. An immediate response was seen within the first hour, and the patient's MetHb levels dropped to $16 \%$ after 2 hours. His cyanosis had resolved (Figure 2), and the GCS returned to 15. The patient was admitted to the ward for observation and was discharged after 2 days well with MetHb levels within normal limits.

Informed consent was signed by the patient on admission and included the use of clinical data for teaching and scientific purposes, and the publication of this case was agreed by the patient and the institution.

\section{DISCUSSION}

\section{Clinical presentation of methemoglobinemia}

Patients with methemoglobinemia usually present dyspnea, pallor, cyanosis, and hypoxia that does not improve with supplemental oxygen administration. The clinical manifestations of this condition are directly correlated with the level of measured MetHb and underlying comorbidities. ${ }^{1}$ In more than half of the cases with acquired methemoglobinemia, the patients are initially not aware of being exposed to an exogenous agent that may have led to their symptoms. Dapsone and local anesthetic agents are often involved in these cases. They are also commonly used to lace "street drugs" and are known to represent a common cause of unexplained acquired methemoglobinemia for some patients.

\section{Diagnosis of methemoglobinemia}

Clinical suspicion of methemoglobinemia should arise in cases of refractory hypoxemia despite supplemental oxygen and a chocolate brown-colored blood sample. COoximetry is an important tool for establishing a conclusive diagnosis, using blood gas analyzers that are able to detect methemoglobin, or a direct assay for methemoglobin, e.g. the Evelyn-Malloy method.2,3

It is important to note that a pulse oximeter can only measure the relative absorbance of two wavelengths of light (660 $\mathrm{nm}$ and $940 \mathrm{~nm}$ ), and this differentiates oxyhemoglobin from deoxyhemoglobin. Methemoglobin increases the absorption of light at both wavelengths (more at $940 \mathrm{~nm}$ ) and therefore offers optical interference to pulse oximetry by falsely absorbing light. This results in an underestima- 
tion of oxygen levels on a pulse oximeter $\left(\mathrm{SpO}_{2}\right)$ when compared to $\mathrm{SaO}_{2}$ from an arterial blood gas. ${ }^{2}$

\section{Methylene blue treatment in methemoglobinemia}

$\mathrm{MB}$ is the treatment of choice in cases of acute toxic methemoglobinemia. It is given in a dose of $1-2 \mathrm{mg} / \mathrm{kg}$ (up to a total of $50 \mathrm{mg}$ in adults, adolescents, and older children) as a $1 \%$ solution in IV saline infused over 3-5 minutes. MB provides an artificial electron transporter for the reduction of MetHb via the NADPH-dependent pathway. The response is usually rapid, and in some cases, the dose may be repeated after one hour if the level of MetHb still remains high. ${ }^{3}$ A rebound methemoglobinemia may occur up to 18 hours after the initial MB administration, due to prolonged absorption of lipophilic agents (benzocaine) from adipose tissue. ${ }^{4}$ The administration of MB may turn sweat, urine, and stools temporarily blue or a greenish hue (Figure 4).

It is also important to note that MB is contraindicated in individuals with glucose-6-phosphate dehydrogenase (G6PD) deficiency. ${ }^{5}$ In such cases, exchange transfusion and hyperbaric oxygen treatment are good second-line options.

\section{CONCLUSION}

Methemoglobinemia should be suspected in any patient with refractory cyanosis, and early recognition of this condition could be potentially lifesaving.

\section{CONFLICT OF INTEREST}

Nothing to declare.

\section{REFERENCES}

1. Agarwal A, Prchal JT. Methemoglobinemia and other causes of cyanosis. In: Williams Hematology, 9th ed, Kaushansky K, Litchtman MA, Prchal JT, et al (Eds). McGraw Hill, New York, 2015; p. 789.

2. Percy MJ, Gillespie MJ, Savage G, Hughes AE, McMullin MF, Lappin TR. Familial idiopathic methemoglobinemia revisited: original cases reveal 2 novel mutations in $\mathrm{NADH}$-cytochrome b5 reductase. Blood. 2002:100(10):3447-3449.

3. Leroux A, Junien C, Kaplan J, Bamberger J. Generalised deficiency of cytochrome b5 reductase in congenital methaemoglobinaemia with mental retardation. Nature. 1975;258(5536):619-620

4. David SR, Sawal NS, Hamzah MNSB, Rajabalaya R. The blood blues: A review on methemoglobinemia. Journal of Pharmacology and Pharmacotherapeutics. 2018;9(1):1-5.

5. Wright RO, Lewander WJ, Woolf AD. Methemoglobinemia: etiology, pharmacology, and clinical management. Ann Emerg Med. 1999;34(5):646656. 